\title{
Impact of Regional Industries on Logistics Demand with Improved Grey Analysis
}

\author{
Wenqin $\mathrm{Cao}^{1,2}$, Haiyan $\mathrm{Zhu}^{3}$, \\ and $\mathrm{Bin} \mathrm{Li}^{4}$ \\ ${ }^{1}$ School of Science, Nanchang University, \\ Nanchang, Jiangxi 330031, China \\ ${ }^{2}$ School of Mechatronics Engineering, East China Jiaotong University, \\ Nanchang, Jiangxi 330013, China \\ ${ }^{3}$ School of Railway Tracks and Transportation, \\ East China Jiaotong University, \\ Nanchang, Jiangxi 330013, China \\ ${ }^{4}$ Institute of Technology East China Jiaotong University, \\ Nanchang, Jiangxi 330100, China \\ bessie2310@163.com
}

\begin{abstract}
An improved Grey Relational Analysis (GRA) is used to quantitatively investigate the impact of Jiangxi Province regional economy on local logistics demand. The grey characteristics of data from regional economy and logistics is studied, which shows GRA is applicable; then a multi-sequence GRA is proposed, which generates total 4 groups of grey relational sequence from three indices of industrial added value and logistics demand based on GRA. Finally statement and explanation are given based on the Jiangxi Provincial industrial situation.
\end{abstract}

Keywords: Logistics Demand, Grey System, Grey Rational Analysis (GRA), Industry.

\section{Introduction}

The planning of regional logistics industry is influenced by multiple complex factors. However, the main factor is always depended on the development of local industries, so an analytical model for relationship between these factors is hard to setup [1]. Hence a study to the development of local economy and its impact on logistics industry will lay the milestone to the logistics planning.

The level of regional economical development, industrial structure, industrial distribution and industrial upgrading has direct impact on the demand and the level of regional logistics [2]. So in this paper, the gray relational theory is used to analyze the impact of Jiangxi provincial regional economy on the local logistics demand from a quantitative respective [4]. 


\section{Applicability of Grey Relational Analysis and Its Improvement}

\subsection{Applicability of Grey Relational Analysis}

The Grey System theory proposed by Deng (1982) has been proven to be useful for dealing with poor, incomplete and uncertain information system called grey system. The Grey System theory is aimed at problems with no experience and insufficient, uncertainty data, which fuzzy mathematics, statistics and probability theory can not solve[4]. Grey Relational Analysis (GRA) is part of Grey System theory, which is suitable for solving problems with complicated interrelationships between multiple factors and variables [5-7]. GRA is to establish gray correlation model to make grey relationship whose operating mechanism and the physical prototype is not clear or non-existent quantification, sequence and obvious. GRA can define system or factor boundary, analyze influence of system and behavior, distinguish primary and secondary factors, identify patterns and so on [8]. Technical connotation of GRA is to obtain difference from variable sequences; establish space of difference; establish and calculate comparison measure of differences, called gray relational grade; establish sequence relationship between factors.

Data of logistics demand is regarded as grey because the statistical data relating with regional logistics demand is not complete for historical reasons, at the same time these statistical data have its flaws ( such as inaccurate, incomplete, estimation, etc.) [9]. Furthermore, socio-economic system is an open system influenced by complexity factors, which is stochastic interacting with after-effect processes and uncertain relationship. The mathematical model for relationship between various economic factors and logistics demand has not been established. Above all, it proves that the relationship between industries and logistics demand shows significant grey characteristic.

\subsection{Variable Definition}

Variable definition is the first step of grey theory application. In the logistics field, almost all goods need transportation, and transportation is first one of the seven logistics activities. So the freight traffic data from the transportation field can be an indicator as logistics demand when logistics demand has no systematic statistics, and be regarded as a reference sequence of GRA model [10]. The scale and level of regional economy directly impact on logistics demand. The statistical Industrial Added Value (IAV) of primary industry, secondary industry and tertiary industry can indicate industrial structure, as compared sequence of GRA model. In our study, the time span of variable data is eight years from 2003 to 2010.

\subsection{Improved GRA Based on Multi-group Grey Relational Grade}

Past research just used only one group of grey relational grade to analyze the degree of influence, because the operational mechanism of grey system was assumed certain 
and unchanged [11]. However, the economy of Jiangxi Province is in the rapid development stage; structure of three industries is adjusted in wider margin variation by years [12]. So model of economic operation is uncertain and variable, which cause relative degree of three factors impact on freight traffic changing. If using only one group of gray relational grade, these changes can not be expressed. The paper introduces multi-group GRA which establishes eight grey relational matrixes, but not just traditional one.

Every sequence of matrix is made of variable data of five consecutive years of 2003 to 2010 by consecutively rolling, that is to say data of year 2003 2007 as group 1, data of year 2004 2008 as group 2,.., and data of year 2006 2010 as group 4 [13]. Finally four groups of grey relational sequence can be gained based on GRA. By horizontal comparison, changes can be grasped dynamically, so analysis is more complete and reliable.

\section{Grey Relational Model and Data Analysis}

\subsection{Source Data and Eight Groups of Matrix}

Variable data is from Jiangxi Statistical Yearbooks. Considering inflation, Industrial Added Value (IAV) of three industries is calculated at 2003 constant prices. All source data is showed in table 1, eight groups of matrix is showed in table 2, which reference sequence is $\mathrm{y}_{0}$ and the comparison sequence is $\mathrm{y}_{\mathrm{i}}$.

Table 1. Added value of three industries and freight traffic from year 2003 to 2010 in jiangxi province

\begin{tabular}{lccccc}
\hline Year & $\begin{array}{l}\text { Freight } \\
(10000 \text { tons })\end{array}$ & $\begin{array}{c}\text { Traffic } \\
\mathrm{y}_{0}\end{array}$ & $\begin{array}{l}\text { IAV of primary } \\
\text { industry (RMB } \\
\text { million), } \mathrm{y}_{1}\end{array}$ & $\begin{array}{l}\text { IAV of Secondary } \\
\text { industry (RMB 100 } \\
\text { million) } \mathrm{y}_{2}\end{array}$ & $\begin{array}{l}\text { IAV of Tertiary industry } \\
\text { (RMB 100 million) } \mathrm{y}_{3}\end{array}$ \\
\hline 2003 & 27709 & 560 & 1227 & 1043 \\
2004 & 31924 & 605 & 1455 & 1143 \\
2005 & 33996 & 644 & 1704 & 1267 \\
2006 & 37517 & 686 & 1982 & 1392 \\
2007 & 40046 & 720 & 2325 & 1541 \\
2008 & 43011 & 755 & 2711 & 1697 \\
2009 & 46237 & 787 & 2968 & 1848 \\
2010 & 54190 & 818 & 3511 & 2047 \\
\hline
\end{tabular}

Notes: Data of IAV in this table are calculated at 2003 constant prices, which is from Jiangxi Statistical Yearbooks. 
Table 2. Four groups of matrix

\begin{tabular}{|l|l|}
\hline $\begin{array}{l}\text { Group1 } \\
\text { (Year 2003 2007) }\end{array}$ & $\begin{array}{l}\mathrm{Y}_{0}(\mathrm{k})=(27709,31924,33996,37517,40046) ; \mathrm{Y}_{1}(\mathrm{k})=(560,605,644,686,720) \\
\mathrm{Y}_{2}(\mathrm{k})=\left(1227,1455,1704,1982,2325 ; \mathrm{Y}_{3}(\mathrm{k})=(1043,1143,1267,1392,1541)\right.\end{array}$ \\
\hline Group2 & $\mathrm{Y}_{0}(\mathrm{k})=(31924,33996,37517,40046,43011) ; \mathrm{Y}_{1}(\mathrm{k})=(605,644,686,720,755)$ \\
(Year 2004 2008) & $\mathrm{Y}_{2}(\mathrm{k})=\left(1455,1704,1982,2325,2711 ; \mathrm{Y}_{3}(\mathrm{k})=(1143,1267,1392,1541,1697)\right.$ \\
\hline Group3 & $\mathrm{Y}_{0}(\mathrm{k})=(33996,37517,40046,43011,46237) ; \mathrm{Y}_{1}(\mathrm{k})=(644,686,720,755,787)$ \\
(Year 2005 2009) & $\mathrm{Y}_{2}(\mathrm{k})=\left(1704,1982,2325,2711,2968 ; \mathrm{Y}_{3}(\mathrm{k})=(1267,1392,1541,1697,1848)\right.$ \\
\hline Group4 & $\mathrm{Y}_{0}(\mathrm{k})=(37517,40046,43011,46237,54190) ; \mathrm{Y}_{1}(\mathrm{k})=(686,720,755,787,818)$ \\
(Year 2006 2010) & $\mathrm{Y}_{2}(\mathrm{k})=\left(1982,2325,2711,2968,3511 ; \mathrm{Y}_{3}(\mathrm{k})=(1392,1541,1697,1848,2047)\right.$ \\
\hline
\end{tabular}

\subsection{Calculation of Grey Relational Grade}

1. Data dimensionless

Source data should be made dimensionless in order to ensure the accuracy of gray correlation calculation, because of their unified units and large difference in value. The three methods commonly used for dimensionless are interval-based method, mean method and initial value method. The initial value method is used as follows:

$$
x_{i k}=\frac{y_{i}(k)}{y_{i}(1)} \quad k=1,2, \cdots, n i=0,1,2, \cdots, m
$$

2. Consideration of grey relational grade

Absolute difference is expressed by Eq (2)

$$
\Delta=\left\{\Delta_{0 i}(k) \mid k=1,2, \ldots n, i=0,1,2, \ldots m\right\}
$$

Environmental parameters are expressed by Eq (3)

$$
M=\max _{i} \max _{k} \Delta_{0 i}(k), \quad m=\min _{i} \min _{k} \Delta_{0 i}(k)
$$

The grey rational coefficient at point $\mathrm{k}$ is defined by Eq (4)

$$
\gamma\left(x_{0 k}, x_{i k}\right)=\frac{m+\xi M}{\Delta_{0 i}(k)+\xi M}, k=1,2, \ldots n ; i=1,2, \ldots m ;
$$

In Deng's study (1989), the general grey relational grade is expressed by Eq (5)

$$
\gamma\left(x_{0}, x_{i}\right)=\frac{1}{n} \sum_{k=1}^{n} \gamma\left(x_{0 k}, x_{i k}\right)
$$

The $\zeta$ is a distinguishing factor, which is set to be 0.5 generally.

Here we adopt the grade computation, and finally the eight groups of grey relational sequence of three industries impact on freight traffic is showed in table 3 , which is retained three decimal. 
Table 3. Eight groups of grey relational sequence of three industries impact on freight traffic

\begin{tabular}{ccccc}
\hline Group Year & $\begin{array}{c}\text { Group 1 } \\
(2003 \sim 2007)\end{array}$ & $\begin{array}{c}\text { Group 2 } \\
(2004 \sim 2008)\end{array}$ & $\begin{array}{c}\text { Group 3 } \\
(2005 \sim 2009)\end{array}$ & $\begin{array}{c}\text { Group 4 } \\
(2006 \sim 2010)\end{array}$ \\
$\begin{array}{c}\text { Primary } \\
\text { industry }\end{array}$ & 0.745 & 0.877 & 0.769 & 0.749 \\
$\begin{array}{c}\text { Secondary } \\
\text { industry } \\
\text { Tertiary } \\
\text { industry }\end{array}$ & 0.649 & 0.610 & 0.594 & 0.550 \\
\hline
\end{tabular}

\subsection{Grey Relational Sequence Analysis}

The higher value of the grey relational grade represents the stronger relational degree between the reference sequence and the given sequence. Table 3 shows that descending order of grey relational coefficient is the primary industry, tertiary industry and secondary industry.

Jiangxi is a granary province, whose Primary industry is developed with a rural population of 32 million, accounting for about $77 \%$ of the total population. Jaingxi allocates to the state 8 to 10 billion kilograms of grain annually, is one of the few provinces with grains output surplus [14].

Jiangxi's future policy and strategies on the Primary industry is to reinforce ecoagricultural construction, whose essential content is to vigorously develop harmless agriculture, green food and organic food. So freight traffic of agricultural produce will still increase [15]. In generally, the agricultural produce's price is low, so its contribution to IAV is limited in the past few years. At the same, outsourcing logistics of Primary industry accounted for a large proportion. From 1998 to 2008, although the IAV from the Primary industries accounted for small proportion of GDP (about $20 \%$ ), The Primary industry has the greatest impact on the freight transportation.

The relationship between the tertiary industry and freight traffic is becoming closer. Rapid development of modern logistics industry raises the level and quality of logistics services effectively, which facilitates the logistics outsourcing in turn [16]. Such virtuous circle makes industrial transport, post and telecommunication industries increase year by year, accounting about $40 \%$ of the tertiary industry.

Although IAV of the secondary industry accounts large proportion of GDP between year 1998 and 2006, about $35 \sim 45 \%$, its gray relational grade is the smallest of the three factors.

With the level of technology improvement, IAV of the secondary industry accounts for a large proportion of production value, and IAV per unit is high. The proportion of logistics outsourcing is low in industrial enterprises.

\section{Conclusions}

The grey rational grades of economic indicators and freight traffic in different province are different because of the different types of provinces and its different economics stages of evolution. 
The improved GRA can be referred to analyze the main factors influencing logistics demand, which will be used to improve logistics industry and coordinate the development of regional economics. It is difficult to establish the physical prototype because of less scientific theory and practice for regional logistics development and planning guidance and more conditions with complex relationship. In the past, regional economic factors and their impact on logistics are limited to qualitative analysis, which is subjectively appraisal, lack of data support. GRA can rule out subjectivity and arbitrariness at a certain extent, which make traditional approach quantitative, scientific and artificial intelligence. Conclusion based on GRA is more comprehensive, objective and impartial.

Further study is considered to the amendment of statistical data. Some Statistical data has its own shortcomings, data of freight traffic has big jump in some years. So further study need revising statistical data to include the strange data and vacancy data to make them more realistic. Then it needs more qualitative method. Many other factors which are eliminated in the model should be analyzed with more qualitative method.

Acknowledgments. The paper is one of the results of project, Reverse Logistics Network Design for Jiangxi Province Based on Circular Economy (GL1114) supported by the provincial education department of Jiangxi, and assisted by key laboratory of conveyance and equipment, ministry of education.

\section{References}

1. Cao, W.-Q.: Logistics demand forecast for urban logistics planning. Master thesis of South China University of technology (2005)

2. Deng, J.: Control problems of grey systems. Systems and Control Letters 1, 288-294 (1982)

3. Williamson, O.E.: Economics and Organization: A Primer. California Management Review 38, 131-146 (1996)

4. Statistic bureau of Jiangxi, Jiangxi statistical yearbook 2009. China Statistics Press (2009)

5. Hibiki, N., Sueyoshi, T.: DEA sensitivity analysis by changing a reference set: regional contribution to Japanese industrial development. Omega 27, 139-153 (1999)

6. $\mathrm{Wu}$, H.H.: A comparative study of using grey relational analysis in multiple attribute decision making problems. Quality Engineering 15, 209-217 (2002-2003)

7. Deng, J.L.: Introduction to grey system theory. The Journal of Grey System 1(1), 1-24 (1989)

8. Yeh, Y.-L., Chen, T.-C.: Application of grey correlation analysis for evaluating the artificial lake site in Pingtung Plain, Taiwan, NRC Annual Report 2003-2004, 56-64 (2004)

9. Wen, K.L.: The cardinal form of grey relational grade. Journal of The Chinese Grey System Association 2(2), 117-133 (1999)

10. Wu, H.J., Chen, C.B.: An alternative form for grey relational grades. The Journal of Grey System 11(1), 7-12 (1999)

11. Lin, C.L.: Use of the Taguchi Method and Grey Relational Analysis to Optimize Turning Operations with Multiple Performance Characteristics. Materials and Manufacturing Processes 19(2), 209-220 (2004) 
12. Lin, Y.-H., Wang, J.-S., Pai, P.-F.: A Grey Prediction Model With Factor, Analysis Technique. Journal of the Chinese Institute of Industrial Engineers 21(6), 535-542 (2004)

13. Chen, W.-H.: A Grey-Based Approach For Distribution Network Reconfiguration. Journal of the Chinese Institute of Engineers 28(5), 795-802 (2005)

14. Chang, J.-C., Lu, H.-C.: Backing Up a Simulated Truck Via Grey Relational Analysis. Journal of the Chinese Institute of Engineers 24(6), 745-752 (2001)

15. Deng, J.L.: Introduction to Grey System Theory. The Journal of Grey System 1, 1-24 (1989)

16. Kuo, Y., Yang, T., Huang, G.-W.: The Use of Grey Relational Analysis in Solving Facilities Layout Design Problem. In: The 36th CIE Conference on Computers \& Industrial Engineering, pp. 1101-1110 (2005) 